\title{
KAJIAN PARTICULATE MATTER DAN KEBISINGAN PADA PERMUKIMAN DI SEKITAR JALAN TOL KEDUNGMUNDU SEMARANG
}

\author{
Andarina Aji Pamurti,S.T.,M.T. a \\ aProgram Studi Perencanaan Wilayah dan Kota Fakultas Teknik Universitas Semarang; Jl. Soekarno Hatta, Tlogosari \\ Kulon, Kec. Pedurungan, Kota Semarang, Jawa Tengah 59160; andarina@usm.ac.id
}

Info Artikel:

- Artikel Masuk: 12/02/21

- Artikel diterima: $20 / 03 / 21$

- Tersedia Online: 30/03/21

\begin{abstract}
ABSTRAK
Pembangunan jalan tol memberikan dampak yang positif untuk mempermudah laju mobilitas masyarakat. Namun pembangunan jalan tol juga memberikan dampak yang negatif pada kawasan permukiman sekitar tol yaitu pencemaran udara akibat pembakaran bahan bakar kendaraan. Partikel udara PM2.5 dan PM10 merupakan partikel yang merusak sistem kerja paru - paru. Kesehatan lingkungan tempat bermukim merupakan penunjang penting yang mempengaruhi kesehatan terutama pada era pandemic covid. Pengukuran partikel udara menggunakan alat portable PM2.5 dan PM10 Air Quality Tester Detector. Rata - rata harian kadar partikel PM2.5 di kawasan permukiman sekitar jalan tol Kedungmundu Semarang adalah 65,44 $\mu \mathrm{g} / \mathrm{Nm}^{3}$, sedangkan kadar partikel PM10 adalah 95,2 $\mu \mathrm{g} / \mathrm{Nm}^{3}$. Kadar PM2.5 melebihi standard dari Baku Mutu Udara Ambien (BMUA) Nasional, The WHO Air Quality Guidline dan Ambient Air Quality Standards (USEPA). Untuk PM10 melebihi standard baku WHO. Selain pencemaran udara, dampak lainnya adalah kawasan permukiman ini memiliki kebisingan. Nilai kebisingan rata - rata harian saat pengukuran waktu sampling adalah 62,23 dB, nilai ini adalah melebihi ambang batas standard Peraturan Menteri Lingkungan Hidup untuk kawasan permukiman. Jadi kawasan permukiman di sekitar jalan tol Kedungmundu Semarang kurang layak bagi kesehatan bila dilihat dari nilai PM 2.5 dan PM10 serta kebisingan. Penelitian ini bertujuan untuk mengetahui tingkat partikel PM2.5 dan PM10 serta kebisingan pada kawasan permukiman di sekitar jalan tol Kedungmundu Semarang. Setelah didapatkan hasil pengukuran, maka akan dapat dijadikan acuan bagi perencana untuk memberikan solusi bagi permukiman yang memiliki dampak akibat aktifitas pembangunan jalan tol dengan intensitas kendaraan yang padat.
\end{abstract}

Kata Kunci : Particulate Matter; Kebisingan; Permukiman

\begin{abstract}
The construction of toll roads has a positive impact to facilitate the mobility rate of the community. But the construction of toll roads also has a negative impact on the residential area around the toll road, namely air pollution due to the burning of vehicle fuel. PM2.5 and PM10 air particles are particles that damage the working system of the lungs. The health of the environment where settled is an important support that affects health, especially in the era of pandemic covid. Air particle measurement using portable PM2.5 and PM10 Air Quality Tester Detector. The daily average level of PM2.5 particles in residential areas around Semarang's Kedungmundu toll road is $65.44 \mu \mathrm{g} / \mathrm{Nm}^{3}$, while the PM10 particle content is $95.2 \mu \mathrm{g} / \mathrm{Nm}^{3}$. PM2.5 levels exceed the standards of the National Ambient Air Quality Standard (BMUA), The WHO Air Quality Guidline and Ambient Air Quality Standards (USEPA). For PM10 exceeds WHO standard. In addition to air pollution, another impact is that these residential areas have noise. The daily average noise value when measuring the sampling time is $62.23 \mathrm{~dB}$, this value is exceeding the standard threshold of the Regulation of the Minister of Environment for residential areas. So the residential area around Kedungmundu Semarang toll road is less feasible for health when viewed from the value of PM 2.5 and PM10 as well as noise. This study aims to determine the level of PM2.5 and PM10 particles as well as noise in residential areas around the Kedungmundu Semarang toll road. Once the measurement results are obtained, it will be used as a reference for planners to provide solutions for settlements that have an impact due to toll road construction activities with dense vehicle intensity.
\end{abstract}

Keywords : Particulate Matter; Noise; Settlements

\section{PENDAHULUAN}

Jalan tol atau yang biasa disebut dengan jalan bebas hambatan merupakan infrastruktur yang disediakan oleh pemerintah guna mempermudah kegiatan mobilitas masyarakat baik itu dalam kota maupun antar kota. Pembangunan jalan tol memberikan dampak yang positif, namun memberikan dampak yang negatif pada kawasan permukiman sekitar tol. 
Kawasan Permukiman di Kedungmundu Semarang berada pada jalur tol Gayam Sari - Jatingaleh. Jalur tol tersebut merupakan jalur padat kendaraan. Dampak yang besar salah satu nya adalah pencemaran udara. Kesehatan lingkungan tempat bermukim merupakan penunjang besar yang mempengaruhi kesehatan masyarakat terlebih dalam keadaan pandemic covid. Kesehatan yang terpenting dalam era pandemic covid adalah kesehatan paru - paru. Kendaraan bermotor merupakan sumber pencemar udara yang berasal dari proses pembakaran bahan bakar. Ukuran partikel dalam udara yaitu PM2.5 dan PM10. Untuk angka 2.5 dan 10 adalah menunjukkan diameter partikel dalam mikron $(\mu)$. Partikel $2.5 \mu \mathrm{m}$ adalah partikel halus memberikan dampak yang signifikan bagi kesehatan. Partikel halus udara sangat berbahaya karena dapat merusak sistem kerja paru - paru dan bahkan menyebabkan kematian.

Selain mengakibatkan pencemaran udara, pembangunan jalan tol juga mengakibatkan kebisingan lingkungan. Permukiman tersebut berada pada persimpangan jalan tol dan jalan raya Kedungmundu. Dua jalan tersebut memiliki intensitas laju kendaraan yang tinggi. Permukiman ini menempel pada bahu jalan tol, tidak terpisah oleh jalan lingkungan, sehingga suara laju kendaraan terdengar sangat jelas. Sumber bising kendaraan terbesar yang melewati jalan tol adalah kendaraan bermuatan berat yang memiliki suara keras dari knalpot yang buruk dan klakson kendaraan.

Aktivitas laju kendaraan warga dalam permukiman yaitu dilintasi kendaraan pribadi dan juga kendaraan pick up dan mobil box yang melintas di sekitar kawasan permukiman. Karena di sekitar Kawasan terdapat tempat usaha penjualan dalam jumlah besar. Kendaraan tersebut padat melintas saat jam kerja yaitu pukul $09.00-16.00$.

Vegetasi di area pemukiman tidak tersebar merata. Terdapat vegetasi di titik tertentu pada kawasan permukiman. Sehingga peredaman dari pencemaran udara dan kebisingan tidak dapat maksimal.

Penelitian ini bertujuan untuk mengetahui tingkat partikel PM2.5 dan PM10 serta kebisingan pada kawasan permukiman di sekitar jalan tol Kedungmundu Semarang. Setelah didapatkan hasil pengukuran, maka akan dapat dijadikan acuan bagi perencana untuk memberikan solusi bagi permukiman yang memiliki dampak akibat aktifitas pembangunan jalan tol dengan intensitas kendaraan yang padat.

\section{DATA DAN METODE}

Setelah dilakukan observasi lingkungan, parameter kualitas udara yang dominan adalah PM2.5 serta PM10. PM2.5 adalah partikel udara $2.5 \mu \mathrm{m}$ dan PM10 adalah partikel udara $10 \mu \mathrm{m}$. Parameter PM2.5 adalah partikel halus yang memberikan dampak yang signifikan bagi kesehatan terutama kesehatan paru - paru. Dan parameter lain yang mendominasi yaitu kebisingan lingkungan.

Pengukuran dilakukan menggunakan alat portable PM2.5 dan PM10 Air Quality Tester Detector. Pengukuran dilakukan dalam waktu 24 jam dengan sampel hari kerja tanggal 18 November 2020. Sedangkan untuk mengukur kebisingan menggunakan alat Sound Level Meter yang dilakukan 7 waktu pengukuran yaitu pukul 07.00,10.00, 15.00, 20.00, 23.00, 01.00 dan 04.00 pada tanggal 18 November 2020. Pengukuran dibaca setiap 5 detik.

Data yang didapat dari hasil pengukuran di lapangan, kemudian dibuat tabel dan grafik untuk diketahui nilai PM2.5, PM10 dan kebisingan dalam udara kawasan permukiman di sekitar jalan tol Kedungmundu Semarang. Yang kemudian data tersebut dibandingkan dengan Peraturan Menteri Lingkungan Hidup telah sesuai dengan standard baku atau tidak. Penelitian ini menggunakan metode kuantitatif yaitu dalam penelitian menggunakan alat, angka, mulai dari pengumpulan data penafsiran terhadap data serta penampilan hasilnya berupa tabel dan grafik.

\section{HASIL DAN PEMBAHASAN}

Berdasar Peraturan Menteri Negara Lingkungan Hidup No. 12 Tahun 2010 tentang Pelaksanaan Pengendalian Pencemaran Udara, tertuang bahwa : 
Tabel 1. Baku Mutu PM2.5 dan PM10

\begin{tabular}{c|c|c|c} 
Parameter & WHO & USEPA & BMUA \\
\hline PM2.5 & 25 & 35 & 65 \\
& $\mu \mathrm{g} / \mathrm{Nm}^{3}$ & $\mu \mathrm{g} / \mathrm{Nm}^{3}$ & $\mu \mathrm{g} / \mathrm{Nm}^{3}$ \\
\hline PM10 & 50 & 150 & 150 \\
& $\mu \mathrm{g} / \mathrm{Nm}^{3}$ & $\mu \mathrm{g} / \mathrm{Nm}^{3}$ & $\mu \mathrm{g} / \mathrm{Nm}^{3}$
\end{tabular}

a. Kualitas Udara PM2.5

Pengukuran kualitas udara pada kawasan permukiman di sekitar jalan tol Kedungmundu Semarang menggunakan alat ukur portable PM2.5 Air Quality Tester Detector. Pengukuran parameter PM2.5 dilakukan di outdoor pada tanggal 18 November 2020. Untuk waktu dilakukan pengukuran 24 jam dari pukul $01.00-24.00$.

Tabel 2. Hasil Pengukuran PM2.5 pada Permukiman di Sekitar Tol Kedungmundu

\section{Semarang}

\begin{tabular}{|c|c|c|c|}
\hline Waktu & PM2.5 & Waktu & PM2.5 \\
\hline (Pukul) & $\left(\mu \mathrm{g} / \mathrm{Nm}^{3}\right)$ & (Pukul) & $\left(\mu \mathrm{g} / \mathrm{Nm}^{3}\right)$ \\
\hline 01.00 & 60,64 & 13.00 & 91,9 \\
\hline 02.00 & 59,79 & 14.00 & 60,63 \\
\hline 03.00 & 62,93 & 15.00 & 66,26 \\
\hline 04.00 & 72,93 & 16.00 & 65,84 \\
\hline 05.00 & 60,81 & 17.00 & 79,36 \\
\hline 06.00 & 47,23 & 18.00 & 89,94 \\
\hline 07.00 & 49,92 & 19.00 & 59,24 \\
\hline 08.00 & 66,93 & 20.00 & 51,3 \\
\hline 09.00 & 76,69 & 21.00 & 51,3 \\
\hline 10.00 & 76,25 & 22.00 & 50,47 \\
\hline 11.00 & 75,69 & 23.00 & 50,47 \\
\hline 12.00 & 93,1 & 24.00 & 51,01 \\
\hline
\end{tabular}

Grafik 1. Hasil Pengukuran PM2.5 pada

Permukiman di Sekitar Tol Kedungmundu Semarang

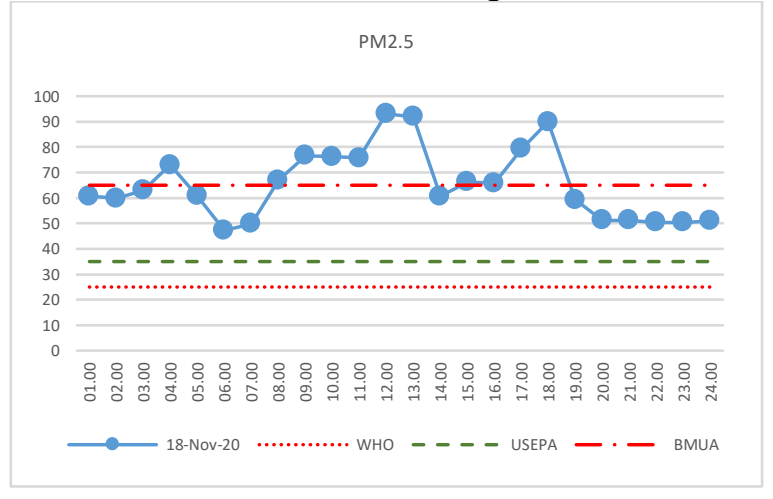

Berdasar hasil pengukuran, rerata harian PM2.5 pada hari Rabu 18 November 2020 adalah $65,44 \mu \mathrm{g} / \mathrm{Nm}^{3}$.

Pada Pukul 12.00 dan 13.00 adalah nilai tertinggi harian. Sedangkan Pukul 24.00 merupakan nilai terendah harian. Pada Pukul 12.00 dan 13.00 terdapat aktivitas padat kendaraan baik dari jalan tol, jalan Kedungmundu dan jalan lingkungan permukiman. Sedangkan Pukul 24.00 aktivitas kendaraan hanya berasal dari jalan tol dan tidak ada aktivitas kendaraan di jalan lingkungan permukiman.

Untuk meredam pencemaran udara menggunakan vegetasi yang ditempatkan menyebar di seluruh titik permukiman, agar peredaman maksimal. Vegetasi tidak hanya ditempatkan di batas permukiman dengan jalan tol saja, tetapi juga penempatan vegetasi yang merata di dalam permukiman, terutama penempatan tanaman di setiap rumah.

\section{b. Kualitas Udara PM10}

Pengukuran kualitas udara pada kawasan permukiman di sekitar jalan tol Kedungmundu Semarang menggunakan alat ukur portable PM10 Air Quality Tester Detector. Pengukuran parameter PM10 dilakukan di outdoor pada tanggal 18 November 2020 yakni pada hari kerja yang memiliki kegiatan dengan padat kendaraan. Pada hari kerja, di permukiman tersebut terdapat kegiatan usaha perdagangan dan juga mobilitas warga yang melakukan kegiatan bekerja. Untuk waktu dilakukan pengukuran 24 jam dari pukul $01.00-24.00$.

Berikut adalah hasil dari pengukuran PM10 kawasan permukiman di sekitar tol Kedungmundu Semarang :

Tabel 3. Hasil Pengukuran PM10 pada Permukiman di Sekitar Tol Kedungmundu Semarang

\begin{tabular}{|c|c|c|c|}
\hline Waktu & PM10 & Waktu & PM10 \\
\hline (Pukul) & $\left(\mu \mathrm{g} / \mathrm{Nm}^{3}\right)$ & (Pukul) & $\left(\mu \mathrm{g} / \mathrm{Nm}^{3}\right)$ \\
\hline 01.00 & 82,62 & 13.00 & 106,48 \\
\hline 02.00 & 88,09 & 14.00 & 106,34 \\
\hline 03.00 & 91,3 & 15.00 & 106,24 \\
\hline 04.00 & 93,79 & 16.00 & 105,08 \\
\hline
\end{tabular}




\begin{tabular}{|c|c|c|c|}
\hline 05.00 & 89 & 17.00 & 101,56 \\
\hline 06.00 & 90,29 & 18.00 & 115,63 \\
\hline 07.00 & 75,4 & 19.00 & 84,93 \\
\hline 08.00 & 100,86 & 20.00 & 88,19 \\
\hline 09.00 & 100,49 & 21.00 & 88,19 \\
\hline 10.00 & 98,25 & 22.00 & 82,41 \\
\hline 11.00 & 107,65 & 23.00 & 82,41 \\
\hline 12.00 & 117,07 & 24.00 & 82,88 \\
\hline
\end{tabular}

Grafik 2. Hasil Pengukuran PM10 pada Permukiman di Sekitar Tol Kedungmundu Semarang

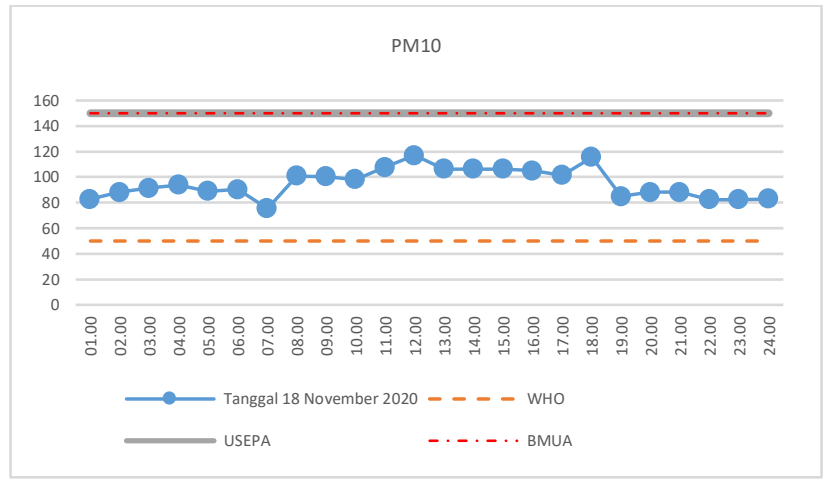

Berdasar hasil pengukuran, rerata harian PM10 pada hari Rabu 18 November 2020 adalah $95,2 \mu \mathrm{g} / \mathrm{Nm}^{3}$ yaitu nilai tersebut diatas ambang yang ditetapkan oleh The WHO Air Quality Guidline.

c. Kebisingan

Berdasar Keputusan Menteri Negara Lingkungan Hidup Nomor

Kep-48/MenLH/11/1996 untuk Kawasan Permukiman memiliki standard baku kebisingan $55 \mathrm{~dB}$.

Tabel 4. Baku Tingkat Kebisingan berdasar Kep-48/MenLH/11/1996

\begin{tabular}{l|l} 
Peruntukan Kawasan & Tingkat Kebisingan (dB)
\end{tabular}

\begin{tabular}{l|c}
\hline $\begin{array}{l}\text { Perumahan dan } \\
\text { Permukiman }\end{array}$ & 55 \\
\hline Perdagangan dan Jasa & 70 \\
\hline $\begin{array}{l}\text { Perkantoran dan } \\
\text { Perdagangan }\end{array}$ & 65 \\
\hline Ruang Terbuka Hijau & 50 \\
\hline Industri & 70 \\
\hline $\begin{array}{l}\text { Pemerintah dan } \\
\text { Fasilitas Umum }\end{array}$ & 60
\end{tabular}

Pengukuran kebisingan pada kawasan permukiman di sekitar jalan tol kedungmundu Semarang dilakukan sampel pada hari kerja. Untuk pengukuran dilakukan 7 kali waktu pengukuran yaitu Pukul 07.00, 10.00, 15.00, 20.00, 23.00, 01.00 dan 04.00 Pengukuran dilakukan di outdoor dengan menggunakan Sound Level Meter. Pengukuran dibaca setiap 5 detik.

Pengukuran kebisingan pada kawasan permukiman di sekitar jalan tol Kedungmundu Semarang dilakukan di outdoor pada tanggal 18 November 2020 yakni pada hari kerja yang memiliki kegiatan dengan padat kendaraan. Pada hari kerja, di permukiman tersebut terdapat kegiatan usaha perdagangan dan juga mobilitas warga yang melakukan kegiatan bekerja.

Tabel 5. Hasil Pengukuran Kebisingan pada Permukiman di Sekitar Tol Kedungmundu Semarang

\begin{tabular}{c|c|c|c|c} 
& Pukul & Pukul & Pukul & Pukul \\
Detik & 07.00 & 10.00 & 15.00 & 20.00 \\
\hline 5 & 54 & 71,7 & 59,4 & 61,5 \\
\hline 10 & 59,7 & 69,2 & 59,2 & 60,6 \\
\hline 15 & 62,6 & 69 & 60,6 & 64,4 \\
\hline 20 & 67,7 & 68,1 & 61,1 & 59,9 \\
\hline 25 & 63,8 & 59,1 & 60,3 & 56,3 \\
\hline 30 & 60,7 & 61,1 & 63,4 & 59 \\
\hline 35 & 63,6 & 61 & 66 & 59,1 \\
\hline 40 & 61,6 & 62,3 & 67,2 & 68,5 \\
\hline 45 & 61,2 & 60,3 & 71,5 & 68,7 \\
\hline 50 & 69,3 & 67,6 & 60,4 & 60,7 \\
\hline 55 & 74,9 & 58,6 & 70,1 & 60 \\
\hline 60 & 60,2 & 61,5 & 67 & 71,2 \\
& Pukul & Pukul & Pukul & Permen \\
Detik & 23.00 & 01.00 & 04.00 & LH \\
\hline 5 & 62 & 58,1 & 71,8 & 55 \\
\hline 10 & 61 & 60,9 & 60,6 & 55 \\
\hline 15 & 58,1 & 70,5 & 58,1 & 55 \\
\hline 20 & 56,8 & 58,3 & 59,8 & 55 \\
\hline 25 & 71,5 & 60,8 & 61,4 & 55 \\
\hline 30 & 61,9 & 54,6 & 58,5 & 55 \\
\hline 35 & 71,1 & 56,9 & 57,2 & 55 \\
\hline 40 & 61,6 & 52,7 & 58,3 & 55 \\
\hline 45 & 61,7 & 53,2 & 57,3 & 55 \\
\hline 50 & 63 & 59,8 & 58,7 & 55 \\
\hline 55 & 61,8 & 59,6 & 58,8 & 55 \\
\hline 60 & 57,6 & 63 & 65,5 & 55
\end{tabular}


Grafik 3. Hasil Pengukuran Kebisingan pada Permukiman di Sekitar Tol Kedungmundu Semarang
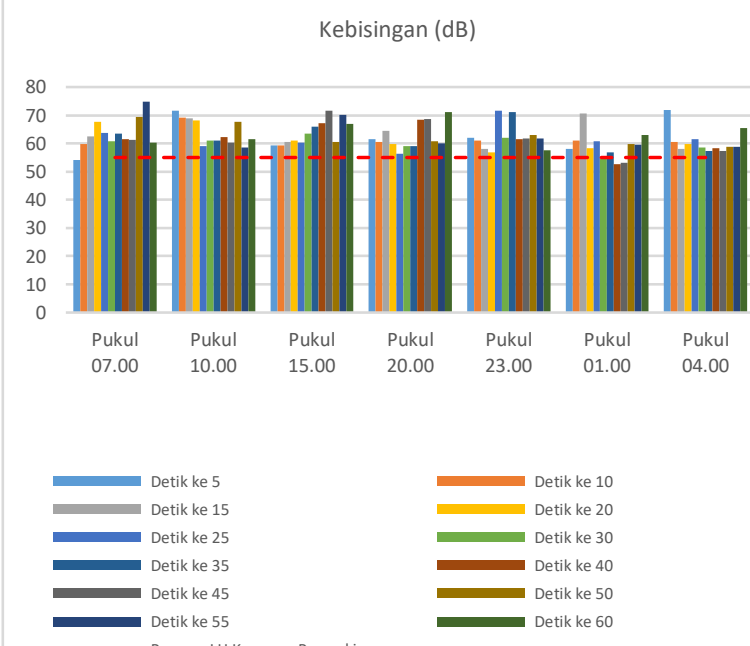

Pada Pukul 07.00 memiliki rerata intensitas kebisingan $63.27 \mathrm{~dB}$, pukul 10.00 yaitu $64.12 \mathrm{~dB}$, pukul 15.00 adalah $63,85 \mathrm{~dB}$, pukul 20.00 yakni $62.49 \mathrm{~dB}$, pukul 23.00 adalah $62,34 \mathrm{~dB}$, pukul 01.00 yaitu $59,03 \mathrm{~dB}$ sedangkan pukul 04.00 adalah $60,5 \mathrm{~dB}$. Pada Pukul 07.00 dan Pukul 15.00 memiliki intensitas kebisingan yang sama tinggi dikarenakan merupakan aktivitas kendaraan pribadi.

Nilai kebisingan tersebut merupakan nilai diatas baku mutu standard yang ditetapkan oleh Menteri Lingkungan Hidup dan Menteri Kesehatan. Oleh karena itu permukiman di sekitar jalan tol Kedungmundu Semarang adalah tidak layak bagi kesehatan.

Untuk kebisingan salah satunya adalah penggunaan vegetasi. Vegetasi yang dapat peredam kebisingan yaitu dengan ciri seperti daun tebal dan kaku serta tingkat kerapatan daun yang tinggi. Penanaman vegetasi merata untuk setiap rumah agar penyerapan kebisingan maksimal.

\section{SIMPULAN}

Rata - rata harian kadar partikel PM2.5 di kawasan permukiman sekitar jalan tol Kedungmundu Semarang adalah $65,44 \mu \mathrm{g} / \mathrm{Nm}^{3}$. Nilai tersebut melebihi baku mutu standard The WHO Air Quality Guidline, National Ambient Air Quality Standards (USEPA) dan berdasar Baku Mutu Udara Ambien (BMUA) Nasional.
Sedangkan rerata harian kadar partikel PM10 adalah 95,2 $\mu \mathrm{g} / \mathrm{Nm}^{3}$. Meskipun nilai tersebut tidak melebihi standard baku mutu Baku Mutu Udara Ambien (BMUA) Nasional dan Ambient Air Quality Standards (USEPA), namun nilai tersebut diatas ambang yang ditetapkan oleh The WHO Air Quality Guidline

Kebisingan harian waktu pengukuran sampling adalah $62,23 \mathrm{~dB}$, nilai tersebut diatas baku mutu standard yang ditetapkan oleh Menteri Lingkungan Hidup dan Menteri Kesehatan.

Jadi kawasan permukiman di sekitar jalan tol Kedungmundu Semarang adalah permukiman yang tidak layak bagi kesehatan karena berada pada batas baku mutu standard yang dtetapkan oleh The WHO Air Quality Guidline, National Ambient Air Quality Standards (USEPA) dan berdasar Baku Mutu Udara Ambien (BMUA) Nasional. Serta tingkat kebisingan melebihi baku mutu yang ditetapkan oleh Menteri Lingkungan Hidup dan Menteri Kesehatan.

Penempatan permukiman sebaiknya diberikan batasan garis sempadan jalan tol, agar meminimalisasi pencemaran udara dan kebisingan. Tidak ditempatkan menempel pada bahu jalan tol.

\section{REFERENSI}

Baku Tingkat Kebisingan No. : Kep48/MenLH/11/1996

Mukhtar,Rita dkk. Komponen Kimia PM2.5 dan PM 10 di Udara Ambien di Serpong Tangerang. Badan Penelitian, Pengembangan dan Inovasi Puslitbang Kualitas dan Laboratorium Lingkungan. 2013.

Pamekas. Pembangunan dan Pengelolaan Infrastruktur Kawasan Permukiman. Bandung : Pustaka Jaya. 2013.

Peraturan Menteri Kesehatan Republik Indonesia tentang Persyaratan Kesehatan Perumahan 829/Menkes/SK/VII/1999

Nomor

Peraturan Menteri Kesehatan Republik Indonesia tentang Pedoman Penyehatan Udara Dalam Ruang Rumah Nomor 1077/Menkes/Per/V/2011.

Peraturan Menteri Negara Lingkungan Hidup tentang Pelaksanaan Pengendalian 
Pencemaran Udara di Daerah Nomor 12 Tahun 2010

Riviwanto, Muchsin. Penyehatan Permukiman Perkotaan. Yogyakarta : Gosyen Publishing. 2017

Sabaruddin, Arief. Permukiman Berkelanjutan. Jakarta : Erlangga. 2016.

Sadana, Agus. Perencanaan Kawasan Permukiman. Yogyakarta : Graha IImu. 2014.

Santosa, Imam. Kesehatan Lingkungan Permukiman Perkotaan. Yogyakarta : Gosyen Publishing 